\title{
Prevalence of testicular adrenal rest tumours in male children with congenital adrenal hyperplasia due to 21-hydroxylase deficiency
}

Hedi L Claahsen-van der Grinten, Fred C G J Sweep ${ }^{1}$, Johan G Blickman ${ }^{2}$, Ad R M M Hermus ${ }^{3}$ and Barto J Otten

Department of Paediatric Endocrinology (833), Radboud University Nijmegen Medical Centre, PO Box 9101, 6500 HB Nijmegen, The Netherlands and Departments of ${ }^{1}$ Chemical Endocrinology (479), ${ }^{2}$ Radiology (667), and ${ }^{3}$ Endocrinology (471), Radboud University Nijmegen Medical Centre, Nijmegen, The Netherlands

(Correspondence to be addressed to H L Claahsen-van der Grinten; Email: h.claahsen@cukz.umcn.nl)

\begin{abstract}
Objective: Testicular adrenal rest tumours (TART) are a well-known complication in adult male patients with congenital adrenal hyperplasia $(\mathrm{CAH})$, with a reported prevalence of up to $94 \%$. In adulthood, the tumours are associated with gonadal dysfunction most probably due to longstanding obstruction of the seminiferous tubules. The aim of our study was to determine the presence of TART and their influence on gonadal function in childhood.

Design: Retrospective study.

Patients and methods: Scrotal ultrasound was performed in 34 children with $\mathrm{CAH}$ due to 21-hydroxylase deficiency who were between 2 and 18 years old. FSH, LH, testosterone and inhibin B concentrations were measured in serum of 27 patients.

Results: TART were detected by ultrasound in 8 out of $34(24 \%)$ children. In two of them, bilateral tumours were found. All lesions were located in the rete testis. Seven patients had the salt-wasting type of CAH; one patient had the simple virilising type of CAH. Mean tumour size was $4.1 \mathrm{~mm}$ (range 2$8 \mathrm{~mm}$ ). In none of the patients were the tumours palpable. Two children with TART were between 5 and 10 years old, the other six children were above 10 years old. In all children with TART, LH, FSH, testosterone and inhibin B levels were similar to the patients without TART.

Conclusion: TART can be found in CAH children before the age of 10 years. The absence of gonadal dysfunction in our group of children suggests that gonadal dysfunction as frequently reported in adult CAH patients with TART develops after childhood.
\end{abstract}

European Journal of Endocrinology 157 339-344

\section{Introduction}

Testicular adrenal rest tumours (TART) are frequently found in adult males with congenital adrenal hyperplasia (CAH) with a reported prevalence of up to $94 \%$ (1). The tumours are always benign. However, because of their typical location within the rete testis, the tumours may lead to obstruction of the seminiferous tubules with possible gonadal dysfunction and infertility (2). Therefore, it may be important to detect and treat the tumours in an early stage. Both ultrasound and MRI are good imaging modalities for the detection and follow-up of TART, especially when they are not palpable on physical examination (3).

The presence of TART in children is described mostly in case reports (4-7) and only a limited number of studies describe its prevalence in larger populations of children and adults (8-10). Avila et al. detected TART by ultrasound in 8 out of 38 male CAH patients (age 6-31 years) (9). The mean age of the patients was 14.8 years and 7 out of the 8 patients with TART were below 18 years old. The youngest patient was 6.2 years old. The total number of investigated patients below 18 years was not reported. Vanzulli et al. described a prevalence of $27 \%$ of TART in a group of $30 \mathrm{CAH}$ patients between 9 and 32 years (10). In the investigation of 24 patients below 18 years, 7 (29\%) had TART. However, these studies did not focus on childhood age and did not present information on gonadal function.

It is suggested that adrenal rest cells in the testes are already present in the embryological period but the onset of tumour growth is not known. Shanklin et al. studied autopsy material of patients with CAH and detected TART in three out of seven patients less than eight weeks old (11). Other studies could not detect testicular tumours by ultrasound before the age of 10 (12).

The aim of our retrospective study was to investigate the incidence of TART in our group of male CAH children. Furthermore, we measured FSH, LH, testosterone and inhibin B levels in this group of CAH children in order to detect possible negative effects of these tumours 
on gonadal function in childhood. In our study group, we show that TART are already present in childhood and gonadal function is not disturbed.

\section{Patients and methods}

\section{Patients}

Scrotal ultrasound was performed in all 34 male children with $\mathrm{CAH}$ due to 21-hydroxylase deficiency who were regularly presented at our outpatient paediatric endocrine unit. The patients were ranged in three age categories: $1-5,5-10$ and $10-18$ years old. The mean age at the first ultrasound was $8 ; 1$ (years;months; range 2;7 to 15;0). In six children, the first scrotal ultrasound was performed before the age of 5 years, in 19 children between 5 and 10 years and in 9 children between 10 and 18 years. Ultrasound scanning was repeated at intervals of $1-2$ years in most patients (Fig. 1).

In all patients, the diagnosis of $\mathrm{CAH}$ was made on symptoms and laboratory tests and was confirmed by mutation analysis. Twenty-four patients had the classical salt-wasting (SW) type, eight patients had the simple virilising (SV) type and two patients had the late onset (LO) type of CAH. All SW patients were diagnosed in the first month of life with exception of patient 6 who had uretral valves. He was falsely diagnosed as having pseudohypoaldosteronism and was treated with salt suppletion only in the first year of life. The diagnosis $\mathrm{CAH}$ in this patient was made not before the age of $1 ; 7$

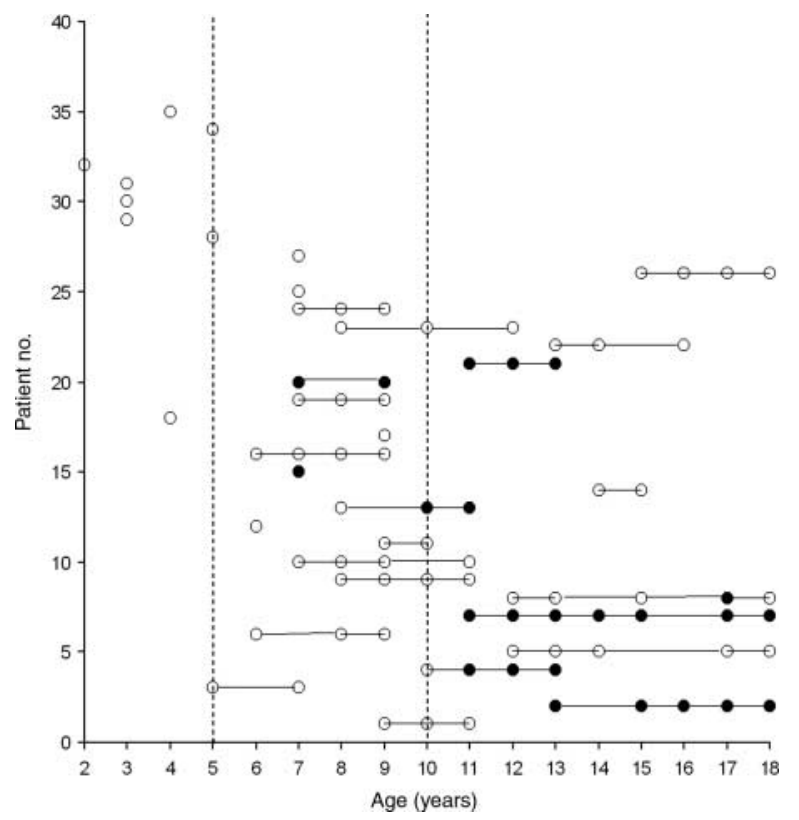

Figure 1 Overview of all scrotal ultrasound investigations in 34 male children with congenital adrenal hyperplasia aged 2 to 18 years. Each circle represents one ultrasound investigation. Open circle, no TART detected; black circles, TART detected. years. All patients were treated with hydrocortisone three times a day and in the case of SW also with fludrocortisone. During follow-up, therapy was monitored each 3 months by evaluating clinical symptoms, anthropometrical measurements (length and weight) and biochemical measurements. Glucocorticoid dosing was monitored by determination of 17-hydroxyprogesterone (17OHP) and androstenedione (A) levels in peripheral blood collected in the morning before taking the glucocorticoid medication in children below 4-5 years old, and by measuring 170HP and A in three saliva samples collected before each of the three doses glucocorticoid medication in older children. Undertreatment was defined as a morning androstenedione concentration before taking the first glucocorticoid dose above the morning reference range for pubertal stage; overtreatment was defined as a morning androstenedione concentration below the morning reference range for pubertal stage (13).

For evaluation of pubertal status the Tanner stages were used (14). Bone maturation was determined according to Greulich \& Pyle (15) in order to determine the hormonal control over years.

\section{Radiological evaluation}

All ultrasonographic evaluations were performed by one out of the three paediatric radiologists in our centre with extensive experience in scrotal ultrasound.

The imaging was done on a 500hdi Philips/ATL model (Philips Medical systems, Bothell, WA, USA) with multi-probe capabilities $(4.5-11 \mathrm{mHz})$ and the lesions were measured by calliper. At least three transverse and axial images of each testis were made, with at least one Doppler image containing the lesion(s). Testicular tumours within the mediastinum testis can be detected by ultrasound when they are at least $2 \mathrm{~mm}$ (3).

\section{Hormone analysis}

Luteinising hormone (LH), follicle-stimulating hormone (FSH), testosterone and inhibin B concentrations in serum were measured in patients above the age of 5 years old. We measured LH and FSH concentrations in 27 children, testosterone concentrations in 26 children and inhibin B concentrations in 23 children. LH and FSH were determined with a Fluorescence Immuno Enzymatic Assay (Abbott) using a Random Access Analyser (Type AxSYM, Abbott). Testosterone was assessed by RIA after pre-purification by means of paper chromatography of ether extracts of the samples, including correction for procedural losses, as described previously $(16,17)$. Dimeric inhibin B was quantified using a solid phase sandwich ELISA specific for measurement of inhibin B in human serum (Oxford Bio-Innovation Ltd, Oxford, UK). The assay was performed according to the manufacturer's instructions. 
Table 1 Mutation analysis, phenotype, age at diagnosis of congenital adrenal hyperplasia (CAH), age at first ultrasound, age at first detection of testicular adrenal rest tumours (TART) and tumour size at first detection in eight CAH children with TART.

\begin{tabular}{|c|c|c|c|c|c|c|c|}
\hline $\boldsymbol{P}$ & Allele $1^{a}$ & Allele $2^{\mathrm{a}}$ & Phenotype $^{b}$ & $\begin{array}{l}\text { Age at diag- } \\
\text { nosis of CAH } \\
\text { (years; months) }\end{array}$ & $\begin{array}{c}\text { Age at first } \\
\text { ultrasound } \\
\text { (years; months) }\end{array}$ & $\begin{array}{c}\text { Age at diag- } \\
\text { nosis of TART } \\
\text { (years; months) }\end{array}$ & $\begin{array}{c}\text { Tumour size at first } \\
\text { detection }\end{array}$ \\
\hline 1 & Del/conv & 329-336 del & SW & Neonatal & $13 ; 10$ & $13 ; 10$ & $\mathrm{~L} 3 \mathrm{~mm}$ and $\mathrm{R} 3 \mathrm{~mm}$ \\
\hline 2 & Del/conv & c. $1066 \mathrm{C}>\mathrm{T}$ & SW & Neonatal & $11 ; 9$ & $11 ; 9$ & $\mathrm{~L} 2 \mathrm{~mm}$ and $\mathrm{R}-$ \\
\hline 3 & $\mathrm{Del} / \mathrm{conv}$ & $\begin{array}{l}\text { c. } 841 \mathrm{G}>\mathrm{T}, \\
\text { c. } 1066 \mathrm{C}>\mathrm{T}, \\
\text { c. } 952 \mathrm{C}>\mathrm{T}\end{array}$ & SW & Neonatal & $8 ; 1$ & $10 ; 1$ & $\mathrm{~L} 4 \times 2 \mathrm{~mm}$ and $\mathrm{R}-$ \\
\hline 4 & $\begin{array}{l}\text { IVS } 2-13, \\
\quad \text { c. } 841 \mathrm{G}>\mathrm{T}\end{array}$ & c. $952 C>T$ & SW & $0 ; 3$ & $7 ; 3$ & $7 ; 3$ & $\mathrm{~L} 5 \mathrm{~mm}$ and $\mathrm{R}-$ \\
\hline 5 & Del/conv & Del/conv & SW & Neonatal & $7 ; 7$ & $7 ; 7$ & $\mathrm{~L}-$ and $\mathrm{R} 3 \mathrm{~mm}$ \\
\hline 6 & c. $1066 \mathrm{C}>\mathrm{T}$ & c. $1066 \mathrm{C}>\mathrm{T}$ & SW & $1 ; 7$ & $11 ; 3$ & $11 ; 3$ & $\mathrm{~L}-$ and $\mathrm{R} 3 \mathrm{~mm}$ \\
\hline 7 & Del/conv & $\begin{array}{l}\text { c.707 T }>A, \\
\text { c.710 T>A, } \\
\text { c.716 T>A }\end{array}$ & SW & Neonatal & $12 ; 2$ & $17 ; 0$ & $\mathrm{~L}-$ and $\mathrm{R} 4 \mathrm{~mm}$ \\
\hline 8 & c. $515 \mathrm{~T}>\mathrm{A}$ & $\begin{array}{l}\text { c. } 707 \mathrm{~T}>\mathrm{A}, \\
\text { c.710 T>A, } \\
\text { c.716 T }>A\end{array}$ & SV & $3 ; 4$ & $10 ; 7$ & $11 ; 9$ & $\mathrm{~L} 6 \mathrm{~mm}$ and $\mathrm{R} 8 \mathrm{~mm}$ \\
\hline
\end{tabular}

$\mathrm{P}$, patient number.

a Nucleotides are numbered according to Higashi's functional CYP21 sequence (26).

${ }^{\mathrm{b}} \mathrm{SW}$, classic salt wasting $\mathrm{CAH}$; SV, classic simple virilising $\mathrm{CAH}$.

\section{Results}

\section{Radiological evaluation}

Figure 1 summarises the age of the first scrotal ultrasound and the frequency of follow-up in all 34 investigated children. TART were detected by ultrasound in 8 out of the 34 investigated children (24\%). In two out of them bilateral tumours were found (nos 1 and 8). The patients' characteristics are listed in Table 1. Seven patients had the SW type and one patient had the SV type of CAH. In none of the patients were tumours the palpable on physical examination. In none of the children in the group below 5 years were TART detected. TART were detected in two children in the group between 5 and 10 years $(10 \%$ of this age group) and in six children in the group between 10 and 18 years old ( $66 \%$ of this age group). The mean tumour size was $4.1 \mathrm{~mm}$ (range $2-8 \mathrm{~mm}$ ). Two children (nos 1 and 2) showed progression of the tumour size on followup ultrasound, one child (no. 7) showed regression of tumour size. All lesions were located near the mediastinum testis and were described as hypoechoic round lesions (Fig. 2), occasionally with an echogenic focus within (Fig. 3).

\section{Gonadal function}

At the time of biochemical evaluation, three patients (nos 1, 2 and 7) had (nearly) completed puberty (Tanner stages IV and V). Two other patients (nos 3 and 8 ) showed no signs of puberty (Tanner stage I). In three patients (nos 4-6) puberty had started (Tanner stage II). In all 27 children in whom biochemical analysis was performed, the LH, FSH, testosterone and inhibin $\mathrm{B}$ concentrations were within the normal range for pubertal stage, with the exception of two $\mathrm{CAH}$ children without TART (age 8 and 7 years old) with isolated increased LH levels. Precocious puberty in these patients was excluded. There was no clear difference in laboratory values between children with and without TART (Fig. 4).

\section{Hormonal control}

Six out of the eight children with TART had a bone age similar to calendar age. Two children showed advanced bone age of maximally 2 years (nos 3 and 5). Five out of the eight children with TART were overtreated at the time of TART diagnosis. Therefore, in these patients the glucocorticoid medication was not increased when

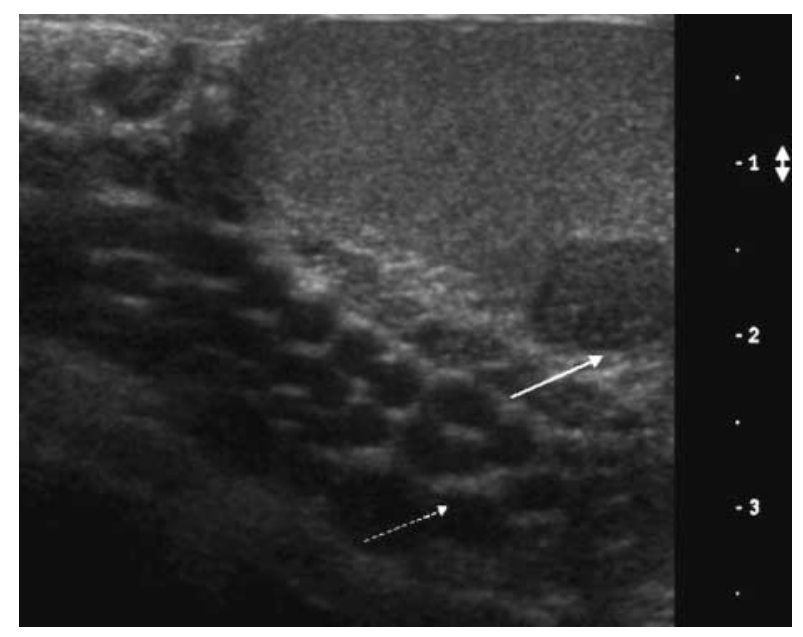

Figure 2 Scrotal ultrasound of patient 2 at the age of 13 years. Transverse image shows a mostly hypoechogenic rounded lesion in the left testis (arrow) near the rete testis (broken arrow). 


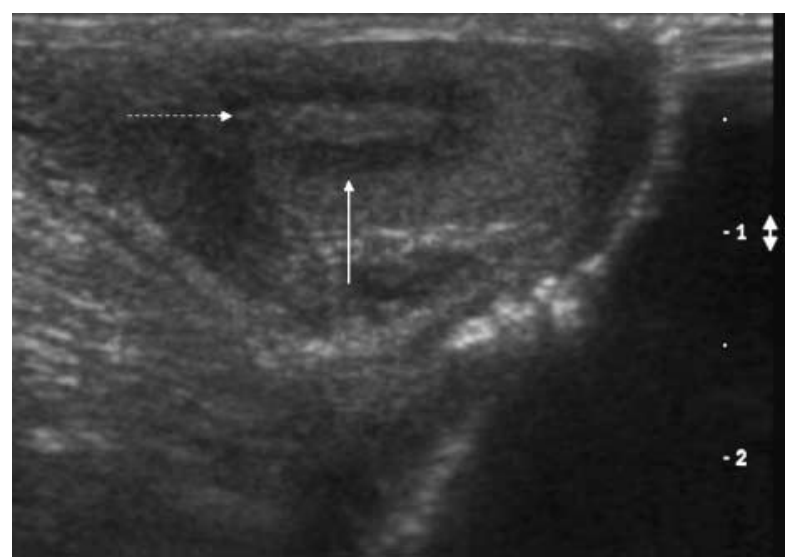

Figure 3 Scrotal ultrasound of patient 6 at the age of 18 years showing a hypoechoic lesion (arrow) with an echogenic centre (broken arrow).

TART was detected. One patient (no. 2) was adequately treated. Also in this patient glucocorticoid medication was not increased because of the suppressed salivary androstenedione levels during the rest of the day. Two patients (nos 1 and 7 ) were undertreated at the time of detection of TART (Table 2): Patient 1 was treated with adequate doses of hydrocortisone but there was lack of compliance. After TART detection, the glucocorticoid doses were increased without any effect on tumour size and with persistently poor compliance until the age of 18 years. In patient 7 , the glucocorticoid dose was increased after detection. Six months later the androstenedione levels were suppressed and the tumour was no longer detectable on ultrasound.

\section{Discussion}

The present study shows that in male CAH children TART are already present in childhood with a prevalence of $24 \%$. This finding is in agreement with previous studies $(9,10)$. However, our study is the first focusing exclusively on childhood age in a larger patient group and gives additional information about gonadal function of $\mathrm{CAH}$ children with and without TART. None of the tumours were detectable by palpation and none of the children with testicular tumours showed signs of gonadal dysfunction.

The aetiology and pathogenesis of TART in CAH patients are not completely understood. Several studies documented the production of adrenal-specific steroids or the presence of adrenal-specific enzymes in these tumours $(18,19)$. Therefore, TART are thought to arise from aberrant adrenal cells in the testes. In the embryological period, cells destined to become adrenal or gonadal cells derive from neighbouring areas of the coelomic epithelium and are morphologically identical (20). During further development, a limited number of 'adrenal' cells may migrate together with the descending testis. Aberrant adrenal tissue within the testes is reported with an incidence of 7.5-15\% (autopsy and surgical findings) in healthy neonates and normally regresses in early infancy (21). Our data suggest that the incidence of aberrant adrenal tissue in the testes is probably underestimated, because under unstimulated conditions aberrant adrenal tissue is difficult to detect. In $\mathrm{CAH}$ patients, aberrant adrenal tissue may grow due to chronically elevated levels of adrenocorticotrophin
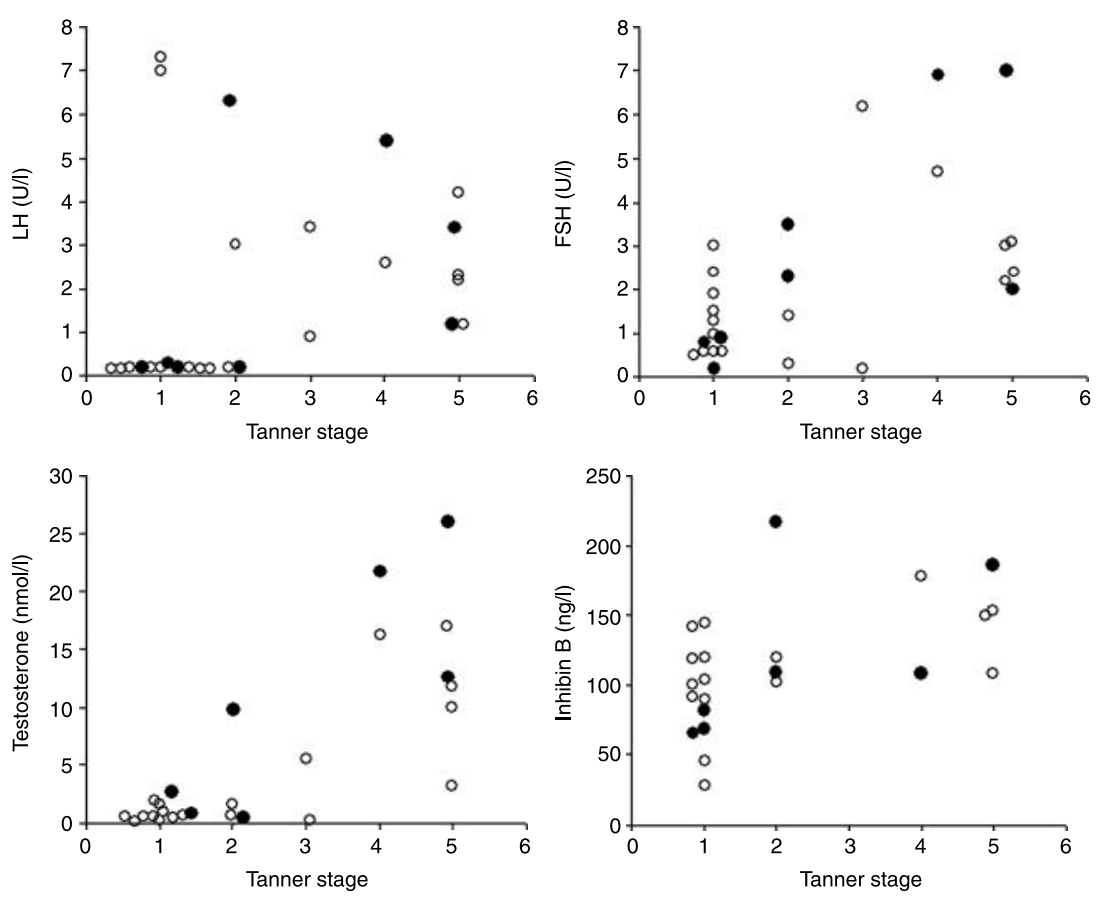

Figure 4 Serum levels of $\mathrm{LH}$, FSH, testosterone and inhibin $\mathrm{B}$ in male $\mathrm{CAH}$ children without TART (open circles) and with TART (closed circles) related to pubertal stages 1-5 according to Tanner. Normal values of $\mathrm{LH}(\mathrm{U} / \mathrm{l})$ depending on pubertal stage $(I-V)$ : median (5-96 percentiles) (27). I $=0.08(<0.05-0.99), I I=0.88$ $(0.11-2.97), \mathrm{III}=2.03(0.51-5.42), \mathrm{IV}=2.89$ (1.11-5.89) and $\mathrm{V}=3.4$ (1.53-6.33). Normal values of $\mathrm{FSH}(\mathrm{U} / \mathrm{L})$ depending on pubertal stage: median (5-96 percentiles) (27). $I=0.85(0.25-2.55), I I=1.95(0.07-$ $4.39), \mathrm{III}=3.5(0.94-9.68), \mathrm{IV}=3.61$ (1.98-6.88) and $V=3.1(1.38-7.52)$. Normal values of testosterone $(\mathrm{nmol} / \mathrm{l})$ depending on pubertal stage: median (5-96 percentiles) (27). $I \leq 0.2(<0.2-0.9), I I=1.9$ $(<0.2-13.4), \mathrm{III}=8.4(0.9-21.2), \mathrm{IV}=17.2$ (7.7-26.5) and $V=21.0$ (11.3-32.3). Normal values of inhibin $B(\mathrm{ng} / \mathrm{l})$ depending on pubertalstage: median (5-96 percentiles) (27). I=78 (35-182), II=195 (62-338), $\mathrm{III}=163(78-323), \mathrm{IV}=188(67-304)$ and $\mathrm{V}=187(95-323)$. 
Table 2 Salivary levels of androstenedione in eight male children at the time of testicular adrenal rest tumours detection.

\begin{tabular}{|c|c|c|c|c|c|}
\hline$P$ & Pubertal stage $^{a}$ & A morning $(\mathrm{nmol} /)^{\mathrm{b}}$ & A noon $(\mathrm{nmol} / \mathrm{l})^{\mathrm{b}}$ & A evening $(\mathrm{nmol} / \mathrm{l})^{\mathrm{b}}$ & Treatment $^{\mathrm{C}}$ \\
\hline 1 & V & 0.94 & 0.65 & 0.5 & Undertreatment \\
\hline 2 & V & 0.25 & 0.1 & 0.08 & Adequate treatment \\
\hline 3 & I & 0.14 & $<0.06$ & 0.04 & Overtreatment \\
\hline 4 & i & $<0.02$ & $<0.02$ & $<0.02$ & Overtreatment \\
\hline 5 & i & 0.07 & $<0.03$ & $<0.036$ & Overtreatment \\
\hline 6 & 1 & 0.08 & 0.04 & $<0.04$ & Overtreatment \\
\hline 7 & IV & 2.7 & 1.6 & 0.62 & Undertreatment \\
\hline 8 & I & 0.061 & 0.03 & $<0.02$ & Overtreatment \\
\hline
\end{tabular}

$\mathrm{P}$, patient number; A, salivary androstenedione levels. Salivary samples were collected three times a day before taking the glucocorticoid medication (morning between 0700 and $0900 \mathrm{~h}$; noon between 1300 and $1500 \mathrm{~h}$ and evening between 2100 and $2300 \mathrm{~h}$ ).

a Pubertal stage according to Tanner (14).

${ }^{\mathrm{b}}$ Normal salivary androstenedione values: Tanner I: $0.02-0.25 \mathrm{nmol} / \mathrm{l}$ and Tanners II-V: $0.14-0.63 \mathrm{nmol} / \mathrm{l}$ (13).

${ }^{c}$ For definitions of undertreatment, overtreatment and adequate treatment see text.

(ACTH) or other unknown growth promoting factors, and may explain the increase in tumour detection by ultrasound during childhood.

The youngest $\mathrm{CAH}$ patient with TART reported in the literature was only several weeks old (11). Recently, we detected a small testicular tumour at post-mortem histopathological examination in a 2-year-old male $\mathrm{CAH}$ patient who died in an Addisonian crisis (unpublished data). The youngest patient with TART in our present study was 7 years old. Therefore, it can be speculated that tumour growth starts during childhood or even in prenatal life.

Until now the exact mechanisms responsible for tumour growth are uncertain. ACTH may be an important stimulator of tumour growth, because ACTH receptors are present on the tumour tissue, and some authors describe a relationship between poor hormonal control and progression of tumour growth $(22,23)$. Although adequacy of substitution therapy was not systematically assessed in our patients, none of our patients had documented periods of poor hormonal control in early childhood or puberty. The absence of advanced skeletal maturation in most patients also favours the notion that hormonal control was adequate in our patients. Most of the TART were detected in children above 10 years old. It can be suggested that hormones whose levels are increased in puberty, such as LH, are additional stimulators of tumour growth. The presence of $\mathrm{LH}$ receptors in testicular tumour tissue supports this hypothesis (24).

It is known that TART have no malignant features. Therefore, there seems to be no need to treat or remove the tumours at an early stage. However, because of the localisation of the tumours in the rete testis, the tumours may compress the seminiferous tubules leading to obstructive azoospermia and irreversible damage of the testes $(2,25)$. Therefore, it is important to detect and treat the tumours before permanent damage of the testis has occurred. Because the growth promoting factors are still unclear, strategies to prevent tumour growth are difficult to define. It has to be investigated whether testis-sparing surgery at an early stage may prevent irreversible testicular damage in later life.
In summary, our study shows that TART are frequently found already in young CAH children. Based on the absence of signs of gonadal dysfunction in our group of children, it seems that gonadal dysfunction, as frequently reported in adult patients, develops after childhood in patients with longstanding tumours. Further studies are necessary to determine whether it is possible to prevent testicular damage by surgical removal of the tumours already in childhood.

\section{References}

1 Stikkelbroeck NMML, Otten BJ, Pasic A, Jager GJ, Sweep CGJ, Noordam K \& Hermus ARMM. High prevalence of testicular adrenal rest tumours, impaired spermatogenesis, and Leydig cell failure in adolescent and adult males with congenital adrenal hyperplasia. Journal of Clinical Endocrinology and Metabolism 2001 86 5721-5728.

2 Claahsen-van der Grinten HL, Otten BJ, Hermus ARMM, Sweep CGJ, Hulsbergen-van de Kaa CA. Testicular adrenal rest tumours in patients with congenital adrenal hyperplasia can cause severe testicular damage. Fertility and Sterility 2007 (In press).

3 Stikkelbroeck NMML, Suliman HM, Otten BJ, Hermus ARMM, Blickman J \& Jager GJ. Testicular adrenal rest tumours in postpubertal males with congenital adrenal hyperplasia: sonographic and MR features. European Radiology $2003 \mathbf{1 3}$ 1597-1603.

4 Newell ME, Lippe BM \& Ehrlich RM. Testis tumors associated with congenital adrenal hyperplasia: a continuing diagnostic and therapeutic dilemma. Journal of Urology 1977117 256-258.

5 Boulware SD. Case report. An unusual case of precocious puberty. Current Opinion in Pediatrics 19979 443-446.

6 Erdogan S, Ergin M, Cevlik F, Yuksel B, Tuncer R, Tunali N \& Polat S. Testicular adrenal rest hyperplasia due to 21-hydroxylase deficiency: a case resport. Endocrine Pathology 200617 83-87.

7 Walker BR, Skoog SJ, Winslow BH, Canning DA \& Tank ES. Testis sparing surgery for steroid unresponsive testicular tumours of the adrenogenital syndrome. Journal of Urology $1997 \quad \mathbf{1 5 7}$ 1460-1463.

8 Willi U, Atares M, Prader A \& Zachmann M. Testicular adrenal-like tissue (TALT) in congenital adrenal hyperplasia: detection by ultrasonography. Pediatric Radiology 199121 284-287.

9 Avila NA, Premkumar A, Shawker TH, Jones JV, Laue L \& Cutler GB. Testicular adrenal rest tissue in congenital adrena hyperplasia: findings at gray-scale and color Doppler US. Radiology $199619899-104$. 
10 Vanzulli A, Delmaschino A, Paesano P, Braggion F, Livieri C, Angeli E, Tomasi G \& Gatti C. Testicular masses in association with adrenogenital syndrome: US findings. Radiology $1992 \mathbf{1 8 3}$ 425-429.

11 Shanklin DR, Richardson AP, Jr \& Rothstein G. Testicular hilar nodules in adrenogenital syndrome. American Journal of Diseases of Children 1963106 243-250.

12 Pierre P, Despert F, Tranquart F, Chabrolle C, Sonnet E, Baron S \& Lecomte P. Adrenal rest tissue in gonads in 66 French patients with congenital adrenal hyperplasia (classic 21 hydroxylase deficiency). Endocrine Society 200621 P3-758.

13 Otten BJ, Wellen JJ, Rijken JC, Stoelinga GB \& Benraad TJ. Salivary and plasma androstenedione and 17-hydroxyprogesterone levels in congenital adrenal hyperplasia. Journal of Clinical Endocrinology and Metabolism 198357 1150-1154.

14 Tanner JM \& Whitehouse RH. Clinical longitudinal standards for height, weight, height velocity, weight velocity, and stages of puberty. Archives of Disease in Childhood 197651 170-179.

15 Greulich WW \& Pyle SI. Radiographic Atlas of Skeletal Development of the Hand and Wrist. 2 Stanford, California: Stanford University Press, 1959.

16 Swinkels LMJW, van Hoof HJC, Ross HA, Smals AGM \& Benraad TJ. Low ratio of androstenedione to testosterone in plasma and saliva of hirsute women. Clinical Chemistry 199238 1819-1823.

17 Swinkels LMJW, Ross HA \& Benraad TJ. A symmetric dialysis method for the determination of free testosterone in human plasma. Clinica Chimica Acta $1987165341-349$.

18 Clark RV, Albertson BD, Munabi A, Cassorla F, Aguilera G, Warren DW, Sherins RJ \& Loriaux DL. Steroidogenic enzyme activities, morphology and receptor studies of a testicular adrenal rest in a patient with congenital adrenal hyperplasia. Journal of Clinical Endocrinology and Metabolism 199070 1408-1413.

19 Bercovici JP, Fiet J, Gibault L, Volant L, Abalain JH, Floch HH, Sonnet E \& Fournier G. Testicular adrenal rest tumours in salt wasting congenital adrenal hyperplasia (in vivo and in vitro studies). Journal of Steroid Biochemistry and Molecular Biology 2005 $9367-72$.

20 Mesinao S \& Jaffe RB. Developmental and functional biology of the primate fetal adrenal cortex. Endocrine Reviews $1997 \mathbf{1 8}$ 378-403.
21 Sullivan JG, Gomel M \& Kinder RB. Ectopic adrenocortical tissue found at groin exploration in children: incidence in relation to diagnosis, age and sex. BJU International 200595 407-410.

22 Stikkelbroeck NML, Hermus ARMM, Suliman HM, Jager GJ \& Otten BJ. Asymptomatic testicular adrenal rest tumours in adolescent and adult males with congenital adrenal hyperplasia: basal and follow-up investigation after 2.6 years. Journal of Pediatric Endocrinology and Metabolism 200417 6645-6653.

23 Claahsen-van der Grinten HL, Otten BJ, Sweep CGJ, Hermus ARMM. Repeated successful induction of fertility after replacing hydrocortisone by equivalent doses of dexamethasone in a patient with congenital adrenal hyperplasia and testicular adrenal rest tumors. Fertility and Sterility 2007 (Epub).

24 Benvenga S, Smedile G, Lo GF \& Trimachi F. Testicular adrenal rests: evidence for luteinizing hormone receptors and for distinct types of testicular nodules differing for their autonomization. European Journal of Endocrinology 1999141 231-237.

25 Claahsen-van der Grinten HL, Otten BJ, Takahashi S, Meuleman EJ, Hulsbergen-van de Kaa C, Sweep CGJ \& Hermus ARMM. Testicular adrenal rest tumours in adult males with congenital adrenal hyperplasia: evaluation of pituitarygonadal function before and after successful testis-sparing surgery in 8 patients. Journal of Clinical Endocrinology and Metabolism 2007 $92612-615$.

26 Higashi Y, Yoshioka H, Yamane M, Gotoh O \& Fujii-Kuriyama Y. Complete nucleotide sequence of two steroid 21-hydroxylase genes tandemly arranged in human chromosome: a pseudogene and a genuine gene. PNAS 198683 2841-2845.

27 Andersson A-M, Juul A, Petersen JH, Mueller J, Groome NP \& Skakkebaek NE. Serum inhibin B in healthy pubertal and adolescent boys: relation to age, stage of puberty and folliclestimulating hormone, luteinizing hormone, testosterone and estradiol levels. Journal of Clinical Endocrinology and Metabolism 199782 3976-3981.

Received 27 March 2007

Accepted 28 May 2007 